\section{RMD Open}

Rheumatic \&

Musculoskeletal Diseases

\title{
Associations between coronary and carotid artery atherosclerosis in patients with inflammatory joint diseases
}

To cite: Svanteson M, Rollefstad S, KIøw NE, et al. Associations between coronary and carotid artery atherosclerosis in patients with inflammatory joint diseases. RMD Open 2017;3:e000544. doi:10.1136/ rmdopen-2017-000544

- Prepublication history and additional material for this paper are available online. To view please visit the journal online (http://dx.doi.org/10.1136/ rmdopen-2017-000544).

AGS and YH contributed equally.

Received 21 July 2017

Accepted 11 August 2017

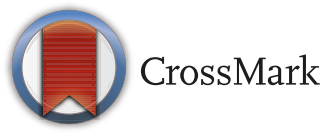

${ }^{1}$ Department of Radiology, 0slo University Hospital, Oslo, Norway ${ }^{2}$ Faculty of Medicine, Institute of Clinical Medicine, University of Oslo, Oslo, Norway

${ }^{3}$ Department of Rheumatology, Preventive Cardio-Rheuma Clinic, Diakonhjemmet Hospital, Oslo, Norway

${ }^{4}$ Department of Vascular Investigations, Oslo University Hospital, Oslo, Norway

Correspondence to Mona Svanteson; mona.svanteson@medisin. uio.no

\section{ABSTRACT}

Objective Low association between cardiac symptoms and coronary artery disease (CAD) in patients with inflammatory joint diseases (IJD) demands for objective markers to improve cardiovascular risk stratification. Our main aim was to evaluate the prevalence and characteristics of CAD in patients with IJD with carotid artery plaques. Furthermore, we aimed to assess associations of carotid ultrasonographic findings and coronary plaques.

Methods Eighty-six patients (61\% female) with IJD (55 with rheumatoid arthritis, 21 with ankylosing spondylitis and 10 with psoriatic arthritis) and carotid artery plaque were referred to coronary CT angiography (CCTA). CAD was evaluated using the modified 17-segment American Heart Association model. Calcium score, plaque composition, segment involvement score and segment stenosis score were assessed and correlated to the carotid artery plaques and cardiovascular disease risk factors in logistic and linear regression analyses. Risk prediction models were tested with various cut-off values for associating variables. Results Fifty-five patients (66\%) had CAD assessed by CCTA and $36(43 \%)$ of these had coronary plaques defined as either mixed or soft. Eleven patients $(13 \%)$ had obstructive CAD. The best risk prediction model (area under the curve: $0.832,95 \% \mathrm{Cl} 0.730$ to 0.935 ) included the combination of variables with cut-off values: age $\geq 55$ years (OR: $12.18,95 \% \mathrm{Cl} 2.80$ to 53.05$)$, the carotid-intima media thickness $\geq 0.7 \mathrm{~mm}$ (OR: $4.08,95 \% \mathrm{Cl} 1.20$ to 13.89) and carotid plaque height $\geq 1.5 \mathrm{~mm}$ (OR: 8.96, 95\% Cl 1.68 to 47.91 ), $p<0.05$.

Conclusion Presence of carotid plaque is alone not sufficient to identify patients at risk for CAD, and a combination of ultrasonographic measurements may be useful in risk stratification of patients with IJD. Trial registration number NCT01389388, Results.

\section{INTRODUCTION}

Patients with inflammatory joint diseases (IJD) have a twofold higher risk of cardiovascular disease compared with the general population. ${ }^{1-3}$ Patients with IJD more often experience silent and fatal coronary events than the general population. ${ }^{4}$ The association between chest pain and coronary artery disease (CAD) is low in patients with $\mathrm{IJD}^{5}$ and it has been

\section{Key messages}

What is already known about this subject?

- Patients with inflammatory joint diseases are at higher risk of developing acute coronary syndrome, and the risk increases in the presence of carotid artery plaques.

- Low association between cardiac symptoms and coronary artery disease demands for objective markers for identification of patients in the need for further cardiac evaluation.

What does this study add?

- We assessed the associations between carotid and coronary plaques in patients with inflammatory joint diseases. The findings suggest that having carotid artery plaque is not alone sufficient for identifying patients with coronary artery disease, and a combination of carotid plaque measurements may be useful in identifying these patients.

How might this impact on clinical practice?

- The study supports the use of carotid ultrasound in cardiovascular risk stratification of patients with inflammatory joint diseases.

reported that the traditional risk stratification tools inadequately predict the risk in patients with rheumatoid arthritis (RA). ${ }^{6}$ Accordingly, objective markers to improve cardiovascular disease risk prediction in patients with IJD are warranted. According to the European guidelines for prevention of cardiovascular disease in the general population, the presence of carotid plaques increases the risk for cardiovascular events, ${ }^{7}$ and several studies support the use of ultrasound of the carotid arteries as a valuable tool for cardiovascular risk stratification in patients with RA. ${ }^{89}$

Although conventional angiography still is the gold standard for assessment of CAD, non-invasive coronary CT angiography (CCTA) has become an established method for excluding coronary artery stenosis in 
patients with chest pain estimated at low or intermediate risk of cardiovascular disease ${ }^{10}$ CCTA also provides valuable information on the presence, localisation and morphology of atherosclerotic plaque(s)..$^{11} 12$

Patients with RA and carotid atherosclerosis have a 2.5-4 times higher risk of acute coronary syndrome compared with patients with RA without carotid plaques. ${ }^{13}$ However, the association of carotid atherosclerosis and CAD, including plaque morphology, in patients with IJD, has to our knowledge not yet been evaluated. Such knowledge will be important for the evaluation of the use of carotid ultrasonography in cardiovascular disease risk stratification in patients with IJD.

The aim of the present study was therefore to evaluate the prevalence and characteristics of coronary plaques in patients with IJD and established carotid artery atherosclerosis. We also aimed to assess associations of coronary plaques with carotid atherosclerosis measurements in order to evaluate the use of ultrasonographic measurements in cardiovascular risk stratification of patients with IJD.

\section{METHODS}

\section{Patients and study design}

The study had a cross-sectional design using baseline data from the RORA-AS study (ROsuvastatin in patients with Rheumatoid Arthritis, Ankylosing Spondylitis and other inflammatory joint diseases). ${ }^{14}$ Patients aged $35-80$ years with IJD participating in the RORA-AS study, who were statin naive and with B-mode ultrasound verified carotid artery plaque(s) were included and referred to CCTA between 2010 and 2012. Contraindication to statin treatment, secondary hyperlipidaemia, atrial fibrillation or arrhythmias were exclusion criteria for participation in the RORA-AS study, as previously more thoroughly described. ${ }^{14}$

All patients were evaluated by a cardiologist before referral to CCTA. Traditional risk factors were recorded, including laboratory testing of lipids and inflammatory markers: C-reactive protein (CRP) and erythrocyte sedimentation rate (ESR).

The study was conducted in accordance with the Helsinki Declaration and approved by the Norwegian South East Regional Health Ethics Committee, registered at http://ClinicalTrials.gov-identifier: NCT01389388 and EudraCT database no. 2008-005551-20. All patients signed an informed consent.

\section{Coronary artery atherosclerosis evaluation \\ CCTA image acquisition}

CCTA imaging was performed with a Philips Brilliance 64-slice CT scanner (Philips Healthcare, Cleveland, Ohio, USA). A beta blocker (5-20 mg Seloken, Astra Zeneca) was administered prior to the CCTA scan to lower the heart rate to $\leq 65$ beats/min (bpm). A non-contrast scan was initially conducted for evaluation of coronary artery calcification (CAC) (ECG gated, $120 \mathrm{kV}, 55 \mathrm{~mA}, 0.4 \mathrm{~ms}$ rotation, $40 \times 0.625 \mathrm{~mm}$ collimation). The contrast-enhanced scan $(90-130 \mathrm{~mL}$ Omnipaque $350 \mathrm{mg} / \mathrm{mL}$ (GE Healthcare, Princeton, New Jersey)) was then performed with prospective ECG gating (conducted with $120 \mathrm{kV}$, $350-500 \mathrm{~mA}, 0.4 \mathrm{~ms}$ rotation, $64 \times 0.625 \mathrm{~mm}$ collimation) when a heart rate $\leq 65 \mathrm{bpm}$ was achieved. Retrospective ECG gating (conducted with $120 \mathrm{kV}, 800 \mathrm{~mA}, 0.2$ Pitch, $0.4 \mathrm{~ms}$ rotation, $64 \times 0.625 \mathrm{~mm}$ collimation) was used for heart rates $\geq 65 \mathrm{bpm}$. Nitroglycerin $0.4 \mathrm{mg}$ (Nitrolingual, Pohl-Boskamp, Hohenlockstedt, Germany) was administered sublingually $1-3 \mathrm{~min}$ prior to the contrast injection.

\section{CCTA image analysis}

Image analysis was performed on a Philips Workstation (Intellispace v5, Philips Healthcare) with dedicated software (Comprehensive Cardiac, Plaque Analysis) with previously reported high degree of interobserver variability. ${ }^{15}$ All images were evaluated by two independent readers, and disagreements were solved by consensus. All segments with subjectively sufficient image quality and a diameter $>1.5 \mathrm{~mm}$ were included in the analyses. Images were assessed using a modified 17-segment American Heart Association (AHA) model. ${ }^{16}$ CAC was calculated with the Agatston method. ${ }^{17}$ The plaque morphology was defined by the amount of calcifications, with a density $>130$ Hounsfield units in the plaque: calcified plaques in the presence of $\geq 50 \%$ calcifications, mixed plaques with less than $<50 \%$ calcifications and soft plaques with no calcifications. $\mathrm{CAD}$ was defined as presence of any plaque.

The extent and severity of CAD was assessed by the segment involvement score and the segment stenosis score. Segment involvement score was calculated as the number of segments with plaque involvement (1-17). Segment stenosis score was calculated for assessment of the severity of the stenosis. Each segment was scored (grading 1-4) based on luminal narrowing: grade 1: 1\%-29\% stenosis; grade 2: $30 \%-49 \%$ stenosis; grade 3: $50 \%-69 \%$ stenosis; grade $4: 70 \%-100 \%$ stenosis, with a total score of $0-68{ }^{18}$

\section{Carotid artery plaque evaluation Ultrasound}

A two-dimensional greyscale (B-mode) ultrasonography of the carotid arteries was performed with a Vivid-7 ultrasound scanner (General Electric Vingmed Ultrasound, Norway) using a $12 \mathrm{MHz}$ linear matrix array transducer. The ultrasonography examinations were performed by one experienced sonographer in accordance with recommendations. ${ }^{19}$ The carotid-intima media thickness (c-IMT) and plaque measurements were as previously described read off-line by two independent readers blinded to patient clinical information. ${ }^{20} \mathrm{c}$-IMT was measured in both the left and right common carotid arteries, and a mean c-IMT was calculated. Our laboratory has previously reported an intraclass correlation coefficient of 0.985 (95\% CI 0.975 to 0.991 ) on c-IMT measurements. ${ }^{20}$ Plaques were identified in the longitudinal view 
as protrusions $>1.5 \mathrm{~mm}$ into the lumen when both the far and near walls had sharp edges, or when the protrusion was $\geq 2$ times the nearby corresponding c-IMT, according to recommendations. ${ }^{21}$

\section{Statistical analyses}

Nominal variables were expressed as numbers (\%), continuous variables as mean \pm SD for normally distributed variables and median with IQR for non-normally distributed variables. Independent samples t-test, $\mathrm{X}^{2}$ tests and analysis of variance were used to compare variables between groups. The analysis of covariance was used to compare groups adjusted for sex, age and hypertension, with log-transformed variables for non-normally distributed variables.

Logistic regression analyses were used to identify variables associated with CAD. All variables with a stronger association than 0.2 in a univariate analysis were included in a multiple logistic regression model. A backward elimination method was performed until only significant predictors remained in the model. The two-sided significance level was set to $<0.05$. Goodness of fit of the model was tested using calibration plots. The same backward method was used to include variables in the multiple linear regression analyses with CAC, segment involvement score and segment stenosis score as dependent variables.

Variables associated with CAD (age, c-IMT and carotid plaque height) were further analysed using multiple logistic regression with various cut-off values. Risk prediction models with various combinations of the three variables were created. Sensitivity and specificity were calculated for the multivariate models to test the diagnostic accuracy of each model and the validity was tested with area under the curve (AUC). All statistical analyses were performed using IBM SPSS V.22.

\section{RESULTS}

\section{Patient characteristics}

A total of 86 patients were referred to CCTA. Three patients only underwent a non-contrast scan due to arrhythmias, and were only included in the CAC analyses. The other 83 patients were included in the final analyses; $53(64 \%)$ with RA, 21 (25\%) with ankylosing spondylitis (AS) and $9(11 \%)$ with psoriatic arthritis (PsA). Table 1 shows the patient characteristics.

Cardiovascular disease risk factors, lipids, medications and inflammatory markers were comparable among patients with RA, AS and PsA. As expected, there were more women in the RA group compared with the AS and PsA groups; 73\%, 33\% and 50\%, respectively.

\section{CAD prevalence and characteristics}

Fifty-five $(66 \%)$ patients had CAD, and the presence of CAD among the three IJD groups was $39(74 \%)$ in the RA group, $13(62 \%)$ in the AS group and $3(33 \%)$ in the PsA group ( $\mathrm{p}=0.13)$ (table 2$)$. Twenty-nine $(53 \%)$ of the patients with CAD had multivessel disease and 11 (20\%) had obstructive $\mathrm{CAD}$ defined as $\geq 50 \%$ stenosis in at least one coronary segment. Conventional angiography confirmed obstructive CAD in 10 of the patients. Three of these patients were treated with percutaneous coronary intervention and the other seven did not receive any intervention after clinical consensus discussions.

Eleven of the $18(61 \%)$ patients with chest pain had $\mathrm{CAD}$, and of these, 4 (22\%) had obstructive CAD. All patients with obstructive CAD had $\mathrm{CAC} \geq 100$. Five (46\%) of these had CAC 100-399 and $6(54 \%)$ had CAC $\geq 400$. Thirty-three (40\%) patients had CAC 0 , and five $(15 \%)$ of these had non-calcified plaques.

In total, plaque findings were detected in $188 / 874$ (22\%) of all segments included in the analysis, with 127 $(68 \%)$ defined as calcified plaques, $51(27 \%)$ as mixed and $10(5 \%)$ as non-calcified.

\section{Associations between coronary atherosclerosis and carotid plaques and cardiovascular risk factors}

Patients with $\mathrm{CAD}$ were older $(\mathrm{p}<0.01)$ and more often hypertensive $(\mathrm{p}=0.01)$ compared with patients without CAD (online supplementary table 1). No significant differences in cardiovascular risk factors, lipids, CRP and ESR were observed between patients with and without CAD.

The number of patients with bilateral plaques was higher in the CAD group than in the group without CAD, 25 (83\%) vs 5 (17\%), respectively, $\mathrm{p}=0.02$. The mean number of plaques in the carotid arteries in the CAD group was $2.1 \pm 1.2$ vs $1.4 \pm 0.8(\mathrm{p}<0.01)$ in those without CAD. There was a difference in mean c-IMT $(0.77 \pm 0.16 \mathrm{~mm}$ vs $0.64 \pm 0.11 \mathrm{~mm}, \mathrm{p}<0.01)$ and carotid plaque height $(2.03 \pm 0.53 \mathrm{~mm}$ vs $1.75 \pm 0.43 \mathrm{~mm}, \mathrm{p}=0.02)$ between those with or without CAD (figure 1). No significant differences were observed between the three IJD entities.

Table 3 presents the associations between CAD and cardiovascular risk factors including the carotid atherosclerosis characteristics. Age (OR: 1.21, 95\% CI:1.081.35), mean c-IMT (OR:1.06, 95\%CI:1.00-1.12)and mean carotid plaque height (OR: 5.35, 95CI:1.29-22.18) were significantly associated with $\mathrm{CAD}$ in a multivariate analysis.

Table 4 shows risk prediction models for diagnostic accuracy of CAD. Models A-F are univariate analyses with cut-off values for the associated variables age, c-IMT and carotid plaque height. Models $\mathrm{G}$ and $\mathrm{F}$ are multivariate models with various combinations of the cut-off values.

The strongest associated univariate models had the following cut-off values: age $\geq 55$ years (OR $17.33,95 \% \mathrm{CI}$ 4.36 to 68.87 ) (model A), c-IMT $\geq 0.7 \mathrm{~mm}$ (OR $4.74,95 \%$ CI 1.76 to 12.76) (model D) and carotid plaque height $\geq 1.5 \mathrm{~mm}$ (OR $6.93,95 \%$ CI 1.67 to 28.79 ) (model E), all $\mathrm{p}<0.01$. When combining these in a multivariate model (model G), the AUC was 0.832 (95\% CI 0.730 to 0.935 ), the sensitivity $94.5 \%$ and the specificity $60.7 \%$.

There was no correlation between carotid atherosclerosis markers $( \pm$ bilateralcarotid plaques, number of 
Table 1 Patient characteristics*

\begin{tabular}{|c|c|c|c|c|c|}
\hline & IJD (n=86) & RA $(n=55)$ & AS $(n=21)$ & PsA $(n=10)$ & p Value \\
\hline Age, years & $60.8 \pm 8.5$ & $62.2 \pm 8.6$ & $58.8 \pm 8.3$ & $57.2 \pm 7.6$ & 0.11 \\
\hline Women, n (\%) & $52(60.5)$ & $40(72.7)$ & $7(33.3)$ & $5(50.0)$ & 0.01 \\
\hline $\begin{array}{l}\text { Disease duration (years), } \\
\text { median (IQR) }\end{array}$ & $16(8.0-25.0)$ & $16(7.0-22.3)$ & $21(9.5-28.0)$ & $11.5(1.5-29.5)$ & 0.19 \\
\hline $\mathrm{BMI}, \mathrm{kg} / \mathrm{m}^{2}$ & $25.3 \pm 3.2$ & $25.0 \pm 2.6$ & $25.4 \pm 2.6$ & $26.4 \pm 3.7$ & 0.44 \\
\hline Waist circumference, $\mathrm{cm}$ & $91.4 \pm 11.1$ & $90.4 \pm 8.6$ & $91.6 \pm 8.6$ & $96.8 \pm 11.3$ & 0.24 \\
\hline Systolic BP, mm Hg & $144 \pm 19$ & $144 \pm 20$ & $145 \pm 13$ & $145 \pm 25$ & 0.94 \\
\hline Diastolic BP, mm Hg & $84 \pm 9$ & $83 \pm 9$ & $85 \pm 9$ & $87 \pm 11$ & 0.53 \\
\hline Hypertension, n (\%) & $51(59.3)$ & $32(58.2)$ & $14(66.7)$ & $4(40.0)$ & 0.76 \\
\hline Diabetes mellitus, $\mathrm{n}(\%)$ & $6(7.0)$ & $4(7.3)$ & $2(9.5)$ & $0(0.0)$ & 0.60 \\
\hline Smoking, n (\%) & $16(18.6)$ & $11(20.0)$ & $3(14.3)$ & $2(20.0)$ & 0.80 \\
\hline $\begin{array}{l}\text { Family history of } \\
\text { cardiovascular disease, } \mathrm{n}(\%)\end{array}$ & $12(14.5)$ & $8(14.5)$ & $1(4.8)$ & $3(30.0)$ & 0.57 \\
\hline $\begin{array}{l}\text { Previous cardiovascular } \\
\text { disease, } \mathrm{n}(\%)\end{array}$ & $9(10.5)$ & $6(10.9)$ & $3(14.3)$ & $0(0.0)$ & 0.47 \\
\hline Angina pectoris, $\mathrm{n}(\%)$ & $18(20.9)$ & $12(28.6)$ & $6(28.6)$ & $0(0.0)$ & 0.33 \\
\hline Hyperlipidaemia, n (\%) & $55(64.0)$ & $33(60.0)$ & $15(71.4)$ & $7(70.0)$ & 0.37 \\
\hline \multicolumn{6}{|l|}{ Lipids } \\
\hline Total cholesterol, mmol/L & $6.4 \pm 1.1$ & $6.4 \pm 1.2$ & $6.3 \pm 0.9$ & $6.5 \pm 1.1$ & 0.88 \\
\hline $\mathrm{HDL}$ cholesterol, $\mathrm{mmol} / \mathrm{L}$ & $1.7 \pm 0.5$ & $1.8 \pm 0.5$ & $1.5 \pm 0.5$ & $1.6 \pm 0.5$ & 0.07 \\
\hline LDL cholesterol, mmol/L & $4.1 \pm 1.0$ & $4.0 \pm 1.1$ & $4.1 \pm 0.9$ & $4.2 \pm 1.0$ & 0.80 \\
\hline $\begin{array}{l}\text { Triglycerides (mmol/L), } \\
\text { median (IQR) }\end{array}$ & $1.2(0.9-1.8)$ & $1.1(0.9-1.6)$ & $1.6(1.1-2.1)$ & $1.1(0.7-2.9)$ & 0.23 \\
\hline \multicolumn{6}{|l|}{ Medications } \\
\hline Synthetic DMARDs, n (\%) & $48(63.2)$ & 34 (68.0) & $6(31.6)$ & $9(90.0)$ & 0.95 \\
\hline Biologic DMARDs, n (\%) & $26(34.2)$ & $16(32.0)$ & $6(31.6)$ & $5(50.0)$ & 0.38 \\
\hline \multicolumn{6}{|l|}{ Inflammatory markers } \\
\hline ESR (mm/hour) & $14.4 \pm 9.3$ & $15.3 \pm 9.6$ & $12.1 \pm 9.8$ & $13.9 \pm 6.0$ & 0.42 \\
\hline CRP (mg/L), median (IQR) & $2.0(1.0-4.0)$ & $3.0(1.0-4.0)$ & $1.0(1.0-5.0)$ & $2.5(1.8-6.5)$ & 0.39 \\
\hline
\end{tabular}

Hypertension, $\geq 140 \mathrm{~mm} \mathrm{Hg}$ systolic, hyperlipidaemia: total cholesterol $\geq 6.0 \mathrm{mmol} / \mathrm{L}$.

*Values expressed as mean \pm SD, unless indicated otherwise.

†Data compared by analysis of variance.

AS, ankylosing spondylitis; BMI, body mass index; BP, blood pressure; CRP, C-reactive protein; DMARDs, disease-modifying antirheumatic drugs; ESR, erythrocyte sedimentation rate; HDL, high-density lipoprotein; IJD, inflammatory joint disease; LDL, low-density lipoprotein;

PsA, psoriatic arthritis; RA, rheumatoid arthritis.

carotid plaques, mean c-IMT and carotid plaque height) and variables representing extent (CAC, segment involvement score) or severity (segment stenosis score).

\section{DISCUSSION}

In this study, the majority of the patients with IJD and established carotid artery plaques had CAD. Calcified coronary plaques were most frequently present, but approximately $40 \%$ of the patients had mixed and/ or soft plaques. We assessed the associations between carotid and coronary plaques. The findings suggest that presence of carotid artery plaque is not alone sufficient for identifying patients with $\mathrm{CAD}$, but a combination of carotid plaque measurements may increase the detectability of these patients.

To our knowledge, only one study has reported on CAD in patients with IJD assessed by CCTA. Karpouzas $e t$ al detected a similar prevalence of CAD $(71 \%)$ in a population consisting of patients with RA without pre-examined carotid arteries or chest pain. ${ }^{22}$ Considering that all patients had carotid plaque(s), CAD was expected to be more frequent in our study; however, the prevalence of CAD in patients with IJD without carotid plaques is not fully elucidated. Although patients with RA with carotid plaques are at higher risk for acute coronary syndrome, there is still a lack of knowledge of early detection of atherosclerosis and its development towards a myocardial 
Table 2 CCTA findings in inflammatory joint diseases

\begin{tabular}{|c|c|c|c|c|c|c|}
\hline \multicolumn{2}{|c|}{ CCTA findings } & All $(n=83)$ & RA (n=53) & AS $(n=21)$ & PsA (n=9) & p Value* \\
\hline \multicolumn{2}{|l|}{ CAD, n (\%) } & $55(66.3)$ & $39(73.6)$ & $12(61.9)$ & $3(33.3)$ & 0.13 \\
\hline \multicolumn{2}{|c|}{ Obstructive CAD, n (\%) } & $11(13.3)$ & $6(54.5)$ & $5(45.5)$ & $0(0.0)$ & 0.46 \\
\hline \multicolumn{2}{|c|}{$\begin{array}{l}\text { Segment involvement score, } \\
\text { mean } \pm S D\end{array}$} & $2.2 \pm 2.7$ & $2.2 \pm 2.5$ & $3.1 \pm 3.3$ & $0.9 \pm 1.5$ & 0.14 \\
\hline \multirow{3}{*}{$\begin{array}{l}\text { Plaque } \\
\text { composition }\end{array}$} & Calcified, n (\%) & $45(54.2)$ & $31(58.5)$ & $11(55.0)$ & $3(30.0)$ & 0.56 \\
\hline & Mixed, n (\%) & $26(31.3)$ & $15(28.3)$ & $9(45.0)$ & $2(20.0)$ & 0.68 \\
\hline & Soft, n (\%) & $10(12.0)$ & $6(11.3)$ & $4(20.0)$ & $0(0.0)$ & 0.34 \\
\hline
\end{tabular}

*Data compared using analysis of covariance (adjusted for sex, age and systolic blood pressure).

AS, ankylosing spondylitis; CAC, coronary artery calcification; CAD, coronary artery disease; CCTA, coronary CT angiography; PsA, psoriatic arthritis; RA, rheumatoid arthritis.

infarction. Interestingly, one-third of the patients in our study did not have CAD, despite having carotid artery plaque. This demonstrates that presence of carotid plaque alone is not sufficient to identify patients at risk for CAD.

The present study suggests both c-IMT and carotid plaque height as significantly associated variables with CAD. However, there is a disagreement in the literature regarding the value of c-IMT with concerns regarding lack of standardisation of definitions and measurements, in addition to high variability and low reproducibility. ${ }^{23}$ Measurements of c-IMT were removed from the AHA guidelines in the assessment of cardiovascular risk in 2013. ${ }^{24}$ However, c-IMT in combination with carotid plaque measurements is recommended as a risk modifier in some cases. ${ }^{23}$ The value of c-IMT in patients with subclinical atherosclerosis regarding cardiovascular disease risk assessment is still unclear. ${ }^{25}$

In the risk prediction models in the present study, age was the variable that showed the strongest association with CAD. Age also had the largest effect on sensitivity. Model $\mathrm{G}$ (cut-off values of $\geq 0.7 \mathrm{~mm}$ for $\mathrm{c}$-IMT and $\geq 1.5 \mathrm{~mm}$ for carotid plaque height) resulted in the highest sensitivity
$(95 \%)$. Sensitivity represents the most crucial value for CAD not to be overlooked; however, a good diagnostic tool also needs a high specificity. The specificity of the aforementioned model was only $61 \%$, which suggests a fairly high rate of false positives. The low specificity in our model can be explained by lack of power, including only 28 patients without CAD in the analysis. Model C was tested with a cut-off for c-IMT of $\geq 0.9 \mathrm{~mm}$, which according to European guidelines is considered abnormal. ${ }^{23}$ Interestingly, this model turned out insignificant. We cannot exclude that this is due to a few number of patients having c-IMT $\geq 0.9 \mathrm{~mm}$ in our study. However, there is a small difference between the models and due to the limitations on c-IMT, clinical applicability may be difficult. Still, the results in our study may support the use of ultrasound (c-IMT and plaque height) in cardiovascular disease risk stratification of patients with IJD, and thus further studies on larger cohorts are warranted. ${ }^{5}$ Risk prediction models are used in clinical decision-making, and can also be helpful in order to provide patients with information and help to make informed choices regarding their health and treatment. Such models may well improve the diagnostic accuracy for prediction of CAD; nevertheless,
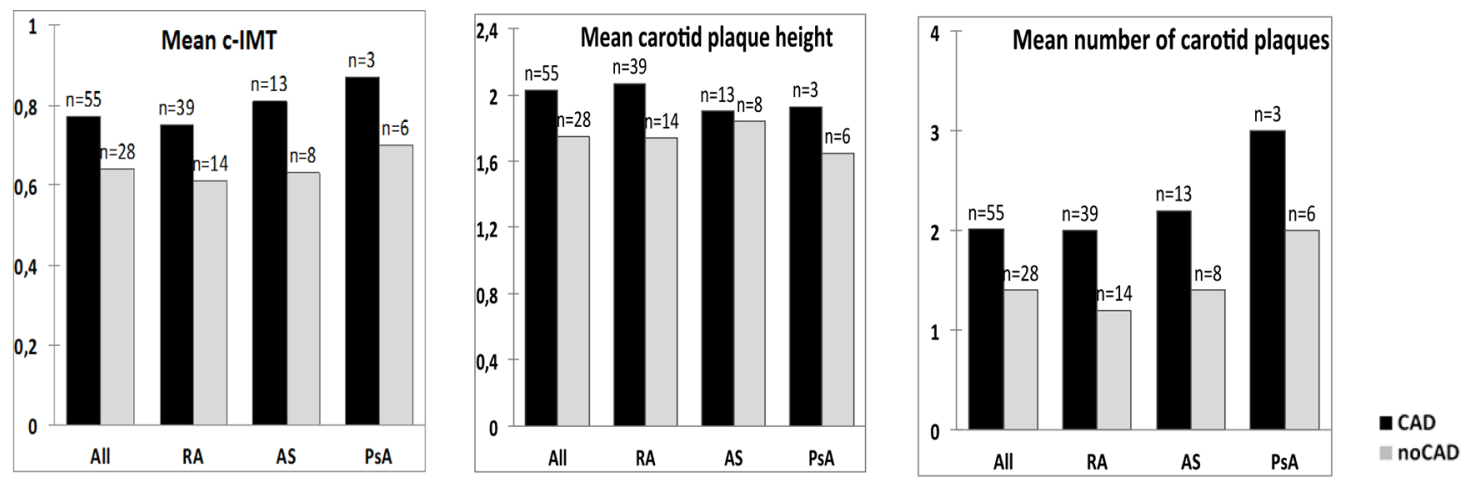

Figure 1 Difference in carotid atherosclerosis measurements (C-IMT, plaque height, number of carotid plaques) between patients with and without CAD. $X^{2}$ analysis including all patients $(n=83)$ : mean c-IMT; $p<0.01$, mean carotid plaque height; $p=0.02$ and mean number of carotid plaques; $p=0.01$. AS, ankylosing spondylitis; c-IMT, carotid-intima media thickness; PsA, psoriatic arthritis; RA, rheumatoid arthritis. 
Table 3 Correlation of coronary artery disease and risk factors

\begin{tabular}{|c|c|c|c|c|}
\hline & \multicolumn{2}{|l|}{ Univariate } & \multicolumn{2}{|l|}{ Multivariate } \\
\hline & OR $(95 \% \mathrm{Cl})$ & p Value & OR $(95 \% \mathrm{Cl})$ & p Value \\
\hline Sex & -0.03 (0.41 to 2.61$)$ & 0.95 & 0.58 (0.14 to 2.42$)$ & 0.46 \\
\hline Age & 0.21 (1.12 to 1.37 ) & $<0.01$ & 1.21 (1.08 to 1.35$)$ & $<0.01$ \\
\hline Hypertension & 1.25 (1.31 to 9.26$)$ & 0.02 & & \\
\hline DMARDs & -0.05 (0.35 to 2.56$)$ & 0.92 & & \\
\hline Biological DMARDs & $-0.89(0.15$ to 1.11$)$ & 0.08 & & \\
\hline Bilateral plaques & 1.34 (1.27 to 11.55$)$ & 0.02 & & \\
\hline Number of carotid plaques & 0.66 (1.12 to 3.37$)$ & 0.02 & & \\
\hline Mean c-IMT & 1.07 (1.03 to 1.12$)$ & $<0.01$ & 1.06 (1.00 to 1.12$)$ & $<0.05$ \\
\hline Carotid plaque height & 1.37 (1.14 to 13.44$)$ & 0.03 & 5.35 (1.29 to 22.18$)$ & 0.02 \\
\hline
\end{tabular}

Logistic regression analyses. Hypertension ( $\geq 140 \mathrm{~mm} \mathrm{Hg}$ systolic).

c-IMT, carotid-intima media thickness; DMARDs, disease-modifying antirheumatic drugs.

they are statistical models that require proof of predictive values for cardiovascular events before they are applied in clinical practice.

Identifying patients in need for further cardiac evaluation would probably be of higher clinical value than solely identifying the presence of CAD. Non-obstructive CAD is an indication for prophylactic drug therapy, and the presence of carotid artery plaque alone is an indication for statin treatment. We found no correlation between variables representing extent $(\mathrm{CAC}$ and segment involvement score) and severity (segment stenosis score) of CAD and the carotid atherosclerosis variables (c-IMT, plaque height and bilateral plaques). These results suggest that these variables may not be useful for identification of extent and severity of CAD. On the other hand, we cannot exclude the possibility that these lacking correlations may represent statistical type II errors considering that we only had 11 patients with obstructive $\mathrm{CAD}$ and an all-over low segment stenosis score.

CAC and CCTA have been reported to have a prognostic value for predicting future coronary events in various cohorts ${ }^{26-28}$; however, the clinical value in asymptomatic individuals needs to be clarified. Corrales et al found a correlation between CACs and c-IMT in 95 patients with RA, but their conclusion was, however, that carotid ultrasonography was more sensitive than CACs for the detection of subclinical atherosclerosis. ${ }^{29}$ No trial has reported on improved outcome due to screening for $\mathrm{CAD}$ in asymptomatic individuals, and previous studies do not recommend CCTA screening

\begin{tabular}{|c|c|c|c|c|c|c|}
\hline & & OR $(95 \% \mathrm{Cl})$ & $p$ Value & Sensitivity & Specificity & AUC $(95 \% \mathrm{Cl})$ \\
\hline A & Age $\geq 55$ years & 17.33 (4.36 to 68.87 ) & $<0.01^{*}$ & $94.5 \%$ & $50.0 \%$ & 0.723 (0.595 to 0.850$)$ \\
\hline B & Age $\geq 60$ years & 7.31 (2.60 to 20.58 ) & $<0.01^{\star}$ & $70.9 \%$ & $75.0 \%$ & 0.730 (0.613 to 0.846$)$ \\
\hline C & Mean c-IMT $\geq 0.9 \mathrm{~mm}$ & $5.28(0.63$ to 44.01$)$ & $0.12^{*}$ & $100.0 \%$ & $0.0 \%$ & 0.564 (0.437 to 0.691$)$ \\
\hline $\mathrm{D}$ & Mean c-IMT $\geq 0.7 \mathrm{~mm}$ & 4.74 (1.76 to 12.76$)$ & $<0.01^{*}$ & $65.5 \%$ & $71.4 \%$ & $0.684(0.563$ to 0.806$)$ \\
\hline$E$ & $\begin{array}{l}\text { Carotid plaque } \\
\text { height } \geq 1.5 \mathrm{~mm}\end{array}$ & 6.93 (1.67 to 28.79 ) & $<0.01^{\star}$ & $94.5 \%$ & $28.6 \%$ & 0.616 (0.481 to 0.751$)$ \\
\hline $\mathrm{F}$ & $\begin{array}{l}\text { Carotid plaque } \\
\text { height } \geq 2.0 \mathrm{~mm}\end{array}$ & 2.27 (0.79 to 6.50$)$ & $0.13^{*}$ & $100.0 \%$ & $0.0 \%$ & 0.584 (0.456 to 0.711$)$ \\
\hline \multirow[t]{3}{*}{ G } & Age $\geq 55$ years & 12.18 (2.80 to 53.05$)$ & $<0.01 \dagger$ & $94.5 \%$ & $60.7 \%$ & $0.832(0.730$ to 0.935$)$ \\
\hline & + Mean c-IMT $\geq 0.7 \mathrm{~mm}$ & 4.08 (1.20 to 13.89$)$ & $0.02 \dagger$ & & & \\
\hline & $\begin{array}{l}\text { +Carotid plaque } \\
\text { height } \geq 1.5 \mathrm{~mm}\end{array}$ & 8.96 (1.68 to 47.91$)$ & $0.01 \dagger$ & & & \\
\hline \multirow[t]{3}{*}{$\mathrm{H}$} & Age $\geq 55$ years & 20.29 (3.82 to 107.90$)$ & $<0.01 \dagger$ & $92.7 \%$ & $64.3 \%$ & 0.866 (0.781 to 0.950$)$ \\
\hline & + Mean c-IMT $\geq 0.8 \mathrm{~mm}$ & 14.98 (2.11 to 106.23$)$ & $<0.01 \dagger$ & & & \\
\hline & $\begin{array}{l}+ \text { Carotid plaque } \\
\text { height } \geq 1.5 \mathrm{~mm}\end{array}$ & 4.50 (0.95 to 21.41$)$ & $0.06 \dagger$ & & & \\
\hline
\end{tabular}

*Univariate logistic regression analysis with CAD as the dependent variable.

AUC, area under the curve; C-IMT, carotid-intima media thickness. 
of high-risk patient groups without cardiac symptoms. An aspect is that CCTA has shown to have relatively high false-positive findings due to an overestimation of the degree of stenosis in the presence of large calcified plaques. ${ }^{30}$ We cannot exclude the possibility that the high amount of CAC in this study may have led to an overestimation of the stenoses measurements. Another consequence of performing CCTA in patients with high CAC may be an increase in complimentary, unnecessary invasive angiographic procedures, which involves exposure to radiation, use of contrast, costs and possible complications.

Finally, the main limitation to this study is the absence of a control group, thereby CAD in patients without any carotid artery plaque remains an unknown factor. This may have influenced our results and we cannot exclude that the correlation between $\mathrm{CAD}$ and the carotid atherosclerosis markers could have been different. We mainly included patients with RA, and the low number of patients in the other groups precludes any further conclusions regarding similarities or differences between the three IJD groups.

Another limitation is the cross-sectional design, which excludes the possibility to evaluate the impact of both carotid and coronary plaques on cardiovascular events in patients with IJD. Studies with longitudinal design are needed to evaluate the clinical value of CCTA and detection of early atherosclerosis in patients with IJD.

In conclusion, our results contribute to the documentation on coronary atherosclerosis in patients with IJD. Our findings suggest that carotid plaque alone is not sufficient to identify patients at risk for CAD. The correlation of c-IMT and carotid plaque height with CAD generates a hypothesis that these parameters may be potential useful markers in cardiovascular disease risk stratification in patients with IJD, and a combination of the variables increases the detectability of patients with CAD. This further supports the use of ultrasound of the carotid arteries in cardiovascular disease risk evaluation in this patient group. ${ }^{9}$ Further studies are needed to evaluate the clinical value of carotid ultrasonography measurements and also CCTA in risk prediction of future coronary artery events in patients with IJD.

Acknowledgements We are grateful to Anne Stormyr Eirheim for performing ultrasound of the carotid arteries, and to Cecilie Okkenhaug for the laboratory procedures.

Contributors AGS, SR and El were responsible for the study design. All authors were responsible for the data acquisition. MS, SR, El, AGS and YH analysed the data. MS wrote the first draft. All authors critically revised the manuscript and approved the final version. AGS and YH share last authorship.

Funding This study has received funding from the South-Eastern Regional Health Authority of Norway.

Competing interests None declared.

Patient consent Obtained

Ethics approval South-Eastern Regional Ethics Committee, Norway.

Provenance and peer review Not commissioned; externally peer reviewed.
Data sharing statement MS, SR and AGS have access to all the data.

Open Access This is an Open Access article distributed in accordance with the Creative Commons Attribution Non Commercial (CC BY-NC 4.0) license, which permits others to distribute, remix, adapt, build upon this work non-commercially, and license their derivative works on different terms, provided the original work is properly cited and the use is non-commercial. See: http://creativecommons.org/ licenses/by-nc/4.0/

(c) Article author(s) (or their employer(s) unless otherwise stated in the text of the article) 2017. All rights reserved. No commercial use is permitted unless otherwise expressly granted.

\section{REFERENCES}

1. Han C, Robinson DW, Hackett MV, et al. Cardiovascular disease and risk factors in patients with rheumatoid arthritis, psoriatic arthritis, and ankylosing spondylitis. J Rheumatol 2006;33:2167-72.

2. Tobin AM, Veale DJ, Fitzgerald O, et al. Cardiovascular disease and risk factors in patients with psoriasis and psoriatic arthritis. $J$ Rheumatol 2010:37:1386-94.

3. Lindhardsen J, Ahlehoff O, Gislason GH, et al. The risk of myocardial infarction in rheumatoid arthritis and diabetes mellitus: a Danish nationwide cohort study. Ann Rheum Dis 2011;70:929-34.

4. Maradit-Kremers H, Nicola PJ, Crowson CS, et al. Cardiovascular death in rheumatoid arthritis: a population-based study. Arthritis Rheum 2005;52:722-32.

5. Rollefstad S, Ikdahl E, Hisdal J, et al. Association of Chest Pain and Risk of Cardiovascular Disease with Coronary Atherosclerosis in Patients with Inflammatory Joint Diseases. Front Med 2015;2:80.

6. Crowson CS, Gabriel SE. Towards improving cardiovascular risk management in patients with rheumatoid arthritis: the need for accurate risk assessment. Ann Rheum Dis 2011;70:719-21.

7. Perk J, De Backer G, Gohlke H, et al. European Guidelines on cardiovascular disease prevention in clinical practice (version 2012): The Fifth Joint Task Force of the European Society of Cardiology and Other Societies on Cardiovascular Disease Prevention in Clinical Practice (constituted by representatives of nine societies and by invited experts). Atherosclerosis 2012;223:1-68.

8. Corrales A, González-Juanatey C, Peiró ME, et al. Carotid ultrasound is useful for the cardiovascular risk stratification of patients with rheumatoid arthritis: results of a population-based study. Ann Rheum Dis 2014;73:722-7.

9. Semb AG, Ikdahl E, Hisdal J, et al. Exploring cardiovascular disease risk evaluation in patients with inflammatory joint diseases. Int $J$ Cardiol 2016;223:331-6.

10. Budoff MJ, Dowe D, Jollis JG, et al. Diagnostic performance of 64-multidetector row coronary computed tomographic angiography for evaluation of coronary artery stenosis in individuals without known coronary artery disease: results from the prospective multicenter ACCURACY (Assessment by Coronary Computed Tomographic Angiography of Individuals Undergoing Invasive Coronary Angiography) trial. J Am Coll Cardiol 2008;52:1724-32.

11. Arbustini $E, D a l$ Bello $B$, Morbini $P$, et al. Plaque erosion is a major substrate for coronary thrombosis in acute myocardial infarction. Heart 1999;82:269-72.

12. van Velzen JE, Schuijf JD, de Graaf FR, et al. Diagnostic performance of non-invasive multidetector computed tomography coronary angiography to detect coronary artery disease using different endpoints: detection of significant stenosis vs. detection of atherosclerosis. Eur Heart J 2011;32:637-45.

13. Evans MR, Escalante A, Battafarano DF, et al. Carotid atherosclerosis predicts incident acute coronary syndromes in rheumatoid arthritis. Arthritis Rheum 2011;63:1211-20.

14. Rollefstad S, Ikdahl E, Hisdal J, et al. Rosuvastatin-Induced Carotid Plaque Regression in Patients With Inflammatory Joint Diseases: The Rosuvastatin in Rheumatoid Arthritis, Ankylosing Spondylitis and Other Inflammatory Joint Diseases Study. Arthritis Rheumatol 2015;67:1718-28.

15. Klass O, Kleinhans $\mathrm{S}$, Walker MJ, et al. Coronary plaque imaging with 256-slice multidetector computed tomography: interobserver variability of volumetric lesion parameters with semiautomatic plaque analysis software. Int J Cardiovasc Imaging 2010;26:711-20.

16. Austen WG, Edwards JE, Frye RL, et al. A reporting system on patients evaluated for coronary artery disease. Report of the Ad Hoc Committee for Grading of Coronary Artery Disease, Council on Cardiovascular Surgery, American Heart Association. Circulation 1975;51(4 Suppl):5-40. 
17. Agatston AS, Janowitz WR, Hildner FJ, et al. Quantification of coronary artery calcium using ultrafast computed tomography. J Am Coll Cardiol 1990;15:827-32.

18. Raff GL, Chinnaiyan KM, Cury RC, et al. SCCT guidelines on the use of coronary computed tomographic angiography for patients presenting with acute chest pain to the emergency department: a report of the Society of Cardiovascular Computed Tomography Guidelines Committee. J Cardiovasc Comput Tomogr 2014;8:254-71.

19. Roman MJ, Naqvi TZ, Gardin JM, et al. Clinical application of noninvasive vascular ultrasound in cardiovascular risk stratification: a report from the American Society of Echocardiography and the Society of Vascular Medicine and Biology. J Am Soc Echocardiogr 2006;19:943-54.

20. Semb AG, Rollefstad S, Provan SA, et al. Carotid plaque characteristics and disease activity in rheumatoid arthritis. $J$ Rheumatol 2013;40:359-68.

21. Touboul PJ, Hennerici MG, Meairs S, et al. Mannheim carotid intima-media thickness and plaque consensus (2004-2006-2011). An update on behalf of the advisory board of the 3rd, 4th and 5th watching the risk symposia, at the 13th, 15th and 20th European Stroke Conferences, Mannheim, Germany, 2004, Brussels, Belgium, 2006, and Hamburg, Germany, 2011. Cerebrovasc Dis 2012;34:290-6.

22. Karpouzas GA, Malpeso J, Choi TY, et al. Prevalence, extent and composition of coronary plaque in patients with rheumatoid arthritis without symptoms or prior diagnosis of coronary artery disease. Ann Rheum Dis 2014;73:1797-804.

23. Piepoli MF, Hoes AW, Agewall S, et al. European Guidelines on cardiovascular disease prevention in clinical practice: The Sixth Joint Task Force of the European Society of Cardiology and Other Societies on Cardiovascular Disease Prevention in Clinical Practice (constituted by representatives of 10 societies and by invited experts) Developed with the special contribution of the European Association for Cardiovascular Prevention \& Rehabilitation (EACPR). Atherosclerosis 2016;2016:207-74.

24. Goff DC, Lloyd-Jones DM, Bennett G, et al. 2013 ACC/AHA guideline on the assessment of cardiovascular risk: a report of the American College of Cardiology/American Heart Association Task Force on Practice Guidelines. J Am Coll Cardiol 20142014;63(25 Pt B):2935-59;63(25 Pt B):2935-59.

25. van den Oord SC, Sijbrands EJ, ten Kate GL, et al. Carotid intimamedia thickness for cardiovascular risk assessment: systematic review and meta-analysis. Atherosclerosis 2013;228:1-11.

26. Blanke P, Naoum C, Ahmadi A, et al. Long-Term Prognostic Utility of Coronary CT Angiography in Stable Patients With Diabetes Mellitus. JACC Cardiovasc Imaging 2016:9:1280-8.

27. Andreini D, Pontone G, Mushtaq S, et al. A long-term prognostic value of coronary CT angiography in suspected coronary artery disease. JACC Cardiovasc Imaging 2012;5:690-701.

28. Hulten E, Villines TC, Cheezum MK, et al. Usefulness of coronary computed tomography angiography to predict mortality and myocardial infarction among Caucasian, African and East Asian ethnicities (from the CONFIRM [Coronary CT Angiography Evaluation for Clinical Outcomes: An International Multicenter] Registry). Am J Cardiol 2013;111:479-85.

29. Corrales A, Parra JA, González-Juanatey C, et al. Cardiovascular risk stratification in rheumatic diseases: carotid ultrasound is more sensitive than Coronary Artery Calcification Score to detect subclinical atherosclerosis in patients with rheumatoid arthritis. Ann Rheum Dis 2013;72:1764-70.

30. Qi L, Tang LJ, Xu Y, et al. The Diagnostic Performance of Coronary CT Angiography for the Assessment of Coronary Stenosis in Calcified Plaque. PLoS One 2016;11:e0154852. 